\title{
Adenovirus-mediated interference of FABP4 regulates mRNA expression of ADIPOQ, LEP and LEPR in bovine adipocytes
}

\author{
S. Wei ${ }^{1,3}$, L.S. Zan ${ }^{1,2}$, H.B. Wang ${ }^{1}$, G. Cheng ${ }^{1}$, M. Du ${ }^{3}$, Z. Jiang ${ }^{3}$, \\ G.J. Hausman ${ }^{4}$, D.C. McFarland ${ }^{5}$ and M.V. Dodson ${ }^{3}$ \\ ${ }^{1}$ College of Animal Science and Technology, Northwest A\&F University, \\ Yangling, Shaanxi, P.R. China \\ ${ }^{2}$ National Beef Cattle Improvement Center, Yangling, Shaanxi, P.R. China \\ ${ }^{3}$ Department of Animal Sciences, Washington State University, \\ Pullman, WA, USA \\ ${ }^{4}$ United States Department of Agriculture, Agriculture Research Services, \\ Athens, GA, USA \\ ${ }^{5}$ Department of Animal Science, South Dakota State University, \\ Brookings, SD, USA
}

Corresponding authors: L.S. Zan / M.V. Dodson

E-mail: zanls@yahoo.com.cn / dodson@wsu.edu

Genet. Mol. Res. 12 (1): 494-505 (2013)

Received May 9, 2012

Accepted September 13, 2012

Published January 4, 2013

DOI http://dx.doi.org/10.4238/2013.January.4.21

\begin{abstract}
Fatty acid binding protein 4 (FABP4) is an important adipocyte gene, with roles in fatty acid transport and fat deposition in animals as well as human metabolic syndrome. However, little is known about the functional regulation of FABP4 at the cellular level in bovine. We designed and selected an effective shRNA (small hairpin RNA) against bovine FABP4, constructed a corresponding adenovirus (AD-FABP4), and then detected its influence on mRNA expression of four differentiation-related genes (PPAR $\gamma, \mathrm{CEBPA}, \mathrm{CEBPB}$, and SREBF1) and three lipid metabolism-related genes (ADIPOQ, LEP and LEPR) of adipocytes. The FABP4 mRNA content, derived from bovine adipocytes, decreased by $41 \%(\mathrm{P}<0.01)$ after $24 \mathrm{~h}$ and $66 \%(\mathrm{P}<0.01)$
\end{abstract}


after $72 \mathrm{~h}$ of AD-FABP4 infection. However, lower mRNA content of FABP4 did not significantly alter levels of differentiation-related gene expression at $24 \mathrm{~h}$ following AD-FABP4 treatment of bovinederived preadipocytes ( $\mathrm{P}=0.54,0.78,0.89$, and 0.94 , respectively). Meanwhile, knocking down (partially silencing) FABP4 significantly decreased ADIPOQ $(\mathrm{P}<0.05)$ and LEP $(\mathrm{P}<0.01)$ gene expression after $24 \mathrm{~h}$ of AD-FABP4 treatment, decreased ADIPOQ $(\mathrm{P}<0.01)$ and LEP $(\mathrm{P}<0.01)$ gene expression, but increased LEPR mRNA expression $(\mathrm{P}$ $<0.01$ ) after a 72-h treatment of bovine preadipocytes. We conclude that FABP4 plays a role in fat deposition and metabolic syndrome by regulating lipid metabolism-related genes (such as ADIPOQ, LEP and LEPR), without affecting the ability of preadipocytes to differentiate into adipocytes.

Key words: Adenovirus; Adipocyte; Bovine; FABP4; shRNA

\section{INTRODUCTION}

Health conscience consumers are likely to purchase meat products with healthier/ lesser types/amounts of fat (Dodson et al., 2010a), thus driving research in meat animal adipogenesis (Hausman et al., 2009) and lipid metabolism (Dodson et al., 2010a). Interest in using cattle for research studies has increased during the past few years for other reasons. Sufficient (isolatable) adipose tissue is present in all adipose depots of cattle for cell isolation and comparative evaluation (Dodson et al., 2010b) and a broadening database of research tools is rapidly being developed for bovine adipose research models. Furthermore, previous studies have indicated that the physiology of adipocytes derived from cattle may be different from other well-understood adipocyte models (such as 3T3-L1) (Fernyhough et al., 2007; Taniguchi et al., 2008a,b; Dodson et al., 2010a,c; Poulos et al., 2010). Bovine adipocytes with potential dominance are the cell model of studying adipogenesis and lipid metabolism for improving animal production and serving human health. Thus, it is important to improve our understanding of adipocyte physiology and functions of key adipokines in cattle.

FABP4 (fatty acid binding protein 4), also known as A-FABP (adipocyte fatty acid binding protein), ALBP (adipocyte lipid binding protein), or ap2 (adipocyte protein-2), is a member of the tissue-specific FABP family, which possesses high affinity for fatty acids and is involved in the transport of long-chain fatty acids within the adipocyte (Ockner et al., 1972). Studies suggest that FABP4 is directly related to fatness traits and may be a potential marker for beef tenderness and intramuscular fat content (Michal et al., 2006; Jurie et al., 2007; Hoashi et al., 2008; Barendse et al., 2009; Lee et al., 2010; Mannen, 2011; Narukami et al., 2011; Zhao et al., 2012). However, the FABP4 gene function at the cellular level of cattle remains unclear.

RNA interference is used in detecting gene function and regulation mechanisms by reducing/partially silencing (knocking down) the mRNA produced from gene expression (Fire et al., 1998; Tuschl, 2001) via posttranscriptional gene silencing induced by small RNA fragments (Fire et al., 1998). The specific mRNA of any targeted gene may be elicited by 
either transfection of double-strand silencing RNA (siRNA), small hairpin RNA (shRNA), or stimulating cells to express siRNA by manipulating its genome via vectors. Compared to double-strand RNA injection or transfection of eukaryotic vectors, an adenovirus vector, which could be used in gene therapy, has manifested predominance for primary cell lines, with high transduction efficiency and long-term knockout of gene transcripts. Therefore, an adenovirus vector (pENTR/CMV-GFP/U6 and pAD/BLOCK-IT ${ }^{\mathrm{TM}}$-DEST RNA interference system) carrying four specific shRNA (targeted part of the mRNA derived from bovine FABP4) was selected and used in this study. By using this system, we aimed to select an effective shRNA targeting bovine FABP4 and define the gene function of FABP4 and its involvement in bovine adipocyte gene expression, differentiation and lipid metabolism. The hypothesis tested was that FABP4 manipulation may be used to affect changes in bovine adipocyte physiology.

\section{MATERIAL AND METHODS}

\section{Adenovirus vector, shRNA design and construction}

Adenovirus vector, $\mathrm{pENTR} / \mathrm{CMV}$-GFP/U6 and the pAD/BLOCK-IT ${ }^{\mathrm{TM}}$-DEST system, containing a U6 promoter and green fluorescent protein (GFP) sequences, was used in this experiment. Four pairs (two complementary single-stranded DNA oligonucleotides for each pair) of shRNA against FABP4 mRNA sequences (GenBank accession No. NM_174314.2) were designed synthetically using several online tool designers (Promega, Invitrogen and Whitehead Institute), with the restriction enzyme sites BamHI and XhoI and hairpin construction sequences 5'-GAGTACTG-3' (with restriction enzyme site ScaI), and then synthesized by Invitrogen, Inc. The shRNA start positions and target sequences in FABP4 mRNA were designed as follows: shRNA 202 (5'-GGTGTGGTCACCATTAAAT-3'), shRNA 207 (5'-GGTCACCATTAAATCAGAA-3'), shRNA 261 (5'-GGGCCAGGAATTTGATGAA-3'), and shRNA 304 (5'-GAGCATCGTAAACTTAGAT-3'). The control shRNA (shNC, sequences: 5'-TTCTCCGAACGTGTCACGT-3') without interference potential was synthesized as well. Each annealed double-stranded fragment of shRNA was first cloned into linearized pENTR/ CMV-GFP/U6 and subjected to an initial selection of effective shRNA against the FABP4 gene.

\section{Initial selection of effective shRNA and adenovirus preparation}

FABP4 coding sequences were cloned and inserted into a pDsRed1-C1 vector. The primer sequences for FABP4 were designed as follows: sense - 5'-CCGCTCGAGAAATGTGT GATGCATTTGTAGG-3', antisense - 5'-CGGGATCCTGCTCTCTCATAAACTCTGGT-3' (product size of $414 \mathrm{bp}$, with restriction sites XhoI and BamHI), using the Primer Premier 5.0 software. To get the most efficient shRNA, the purified pENTR/CMV-GFP/U6/shRNAFABP4 and pDsRed1-C1-FABP4 were co-transfected into HEK 293A cells using Lipofectamine $^{\mathrm{TM}} 2000$ (Invitrogen, Inc.). Co-transfected pENTR/CMV-GFP/U6/shRNA-NC and pDsRed1-C1-FABP4 HEK 293A cells were the control groups. Moreover, pENTR/CMVGFP/U6/shRNA-NC and pDsRed1-C1-FABP4 were transfected separately as another group to monitor transfection efficiency. By visualization with an Olympus inverted research micro- 
scope, the pENTR/CMV-GFP/U6/shRNA-FABP4 and pDsRed1-C1-FABP4 plasmids could be observed by GFP and red fluorescent protein (RFP), respectively. As FABP4 and RFP were expressed as a fusion by pDsRed1-C1-FABP4, the efficiency of shRNA targeting FABP4 was detected by the red fluorescent diminish-degree on the third day after co-transfection. The GFP level was used in monitoring the transfection efficiency among groups. This selection was repeated three times with three duplicates each time, and the one with the highest effective shRNA was selected. The selective shRNA was then combined with $\mathrm{pAD} / \mathrm{BLOCK}-$ IT $^{\mathrm{TM}}$-DEST using Gateway ${ }^{\circledR}$ LR Clonase ${ }^{\mathrm{TM}}$ II Enzyme Mix (Invitrogen). By Lipofectamine ${ }^{\mathrm{TM}}$ 2000 (Invitrogen, Inc.), the linearized recombinant plasmid was transfected into HEK 293A cells. AD-FABP4 (adenovirus shRNA against FABP4) was then packaged and amplified until the virus achieved sufficient infection ability. AD-NC, which expressed the negative control (NC) shRNA, was prepared in parallel. Preparation of the adenovirus was in accordance with manufacturer instructions.

\section{Animal/tissue samples}

Perirenal fat was obtained from three newborn Chinese Holstein calves, taken to the cell culture laboratory and immediately soaked in warm PBS containing $100 \mathrm{IU} / \mathrm{mL}$ penicillin-100 $\mu \mathrm{g} / \mathrm{mL}$ streptomycin (pen-strep). The samples from the three calves were handled separately from collection to the treatment detection process. The animal protocol was approved by the Experimental Animal Care and Use Committee of Northwest A\&F University.

\section{Cell isolation, cell culture and viral infection}

The stromal vascular cells (SV cells; preadipocyte fraction) were isolated following the method described by Sun et al. (2009), with minor modifications. Under sterile conditions, adipose tissues were rinsed with warm PBS and cut into small sections. Then, the samples were digested with an equal volume of enzyme solution (DMEM/F12 $+20 \mathrm{~g} / \mathrm{L}$ BSA $+2 \mathrm{~g} / \mathrm{L}$ type I collagenase) for $60 \mathrm{~min}$ at $37^{\circ} \mathrm{C}$ in a shaking water bath. DMEM/F12 containing $10 \%$ FBS was then added to stop the digestion. The solution was passed through $200-\mu \mathrm{m}$ nylon filters and centrifuged at $800 \mathrm{~g}$ for $10 \mathrm{~min}$ to collect cells. The mixed suspension solution was decanted to remove mature adipocytes and enzyme. The bottom pellet was washed three times and re-suspended in DMEM/F12 containing 10\% FBS, pen-strep and plated at a density of $5 \times 10^{4}$ cells $/ \mathrm{cm}^{2}$. The isolated cells were subsequently cultured at $37^{\circ} \mathrm{C}$ in a humidified $5 \%$ $\mathrm{CO}_{2}$ atmosphere. After $24 \mathrm{~h}$, the plates were washed with PBS to remove unattached cells. The medium was changed every 2 days. When the cells reached confluence (day 0 ), they were separated into three groups: AD-FABP4-treated group, AD-NC-treated group and normal control group. The treated cells were exposed to differentiation medium (DMEM/F12 containing $10 \%$ FBS, pen-strep, $100 \mathrm{ng} / \mathrm{mL}$ dexamethasone, $10 \mu \mathrm{g} / \mathrm{mL}$ insulin, $10 \mu \mathrm{g} / \mathrm{mL}$ transferrin) plus infectious AD-FABP4 or AD-NC adenovirus, respectively. The normal control cells were treated only with the differentiation medium. The HEK 293A cell line was cultured in high glucose DMEM plus 10\% FBS. All the cells were incubated in a humidified atmosphere of $37^{\circ} \mathrm{C}$ and $5 \% \mathrm{CO}_{2}$. 


\section{Real-time PCR}

Total RNA was extracted with the E.Z.N.A ${ }^{\mathrm{TM}}$ total RNA kit I (Invitrogen) at 24 and 72 $\mathrm{h}$ after viral infection. The RNA for assay was treated with DNase I for $30 \mathrm{~min}$ to remove the genomic DNA before being dissolved in RNase-free water. The $\mathrm{A}_{260} / \mathrm{A}_{280}$ ratio of purified RNA was between 1.6 and 1.8. Samples were then processed for cDNA synthesis using a reverse transcription kit (Fermentas). Gene expression of four differentiation-related genes ( $\mathrm{PPAR}_{\gamma}$, CEBPA, CEBPB, and SREBF1) and three lipid metabolism-related genes (ADIPOQ, LEP and LEPR) was detected in this experiment. The primer sequences are shown in Table 1. GAPDH and ACTB were used as dual endogenous controls. Real-time PCR was carried out in a 20- $\mu \mathrm{L}$ reaction mixture containing $50 \mathrm{ng}$ cDNA, $0.4 \mu \mathrm{M}$ each primer, $10 \mu \mathrm{L} \mathrm{SYBR}^{\circledR}$ Premix Ex Taq ${ }^{\mathrm{TM}}$ II (TaKaRa Biotechnology, Japan), $0.4 \mu \mathrm{L}$ ROX Reference Dye II (TaKaRa Biotechnology). PCR conditions were as follows: pre-denaturation step at $95^{\circ} \mathrm{C}$ for $30 \mathrm{~s}, 40$ cycles of the PCR steps, namely denaturation at $95^{\circ} \mathrm{C}$ for $5 \mathrm{~s}$ and extension at $60^{\circ} \mathrm{C}$ for $34 \mathrm{~s}$, followed by a dissociation cycle of $95^{\circ} \mathrm{C}$ for $15 \mathrm{~s}, 60^{\circ} \mathrm{C}$ for $1 \mathrm{~min}$ and $95^{\circ} \mathrm{C}$ for $15 \mathrm{~s}$ to obtain the melting curve. All the quantitative RT-PCRs were performed in triplicate on an ABI 7500 machine (Applied Biosystems), based on a standard curve method. All data analysis was performed as recommended by the manufacturer.

Table 1. Primer sequences designed for real-time PCR.

\begin{tabular}{|c|c|c|c|}
\hline Gene name & Accession No. & Primer sequences & Product size (bp) \\
\hline FABP4 & NM_174314.2 & $\begin{array}{l}\text { 5'-TGAGATTTCCTTCAAATTGGG-3' } \\
\text { 5'-CTTGTACCAGAGCACCTTCATC-3' }\end{array}$ & 101 \\
\hline $\operatorname{PPAR}_{\gamma}$ & NM_181024.2 & $\begin{array}{l}\text { 5'-GAGATCACAGAGTACGCCAAG-3' } \\
\text { 5'-GGGCTCCATAAAGTCACCAA-3' }\end{array}$ & 216 \\
\hline CEBPA & NM_176784.2 & $\begin{array}{l}\text { 5'-ATCTGCGAACACGAGACG-3' } \\
\text { 5'-CCAGGAACTCGTCGTTGAA-3' }\end{array}$ & 73 \\
\hline CEBPB & NM_176788.1 & $\begin{array}{l}\text { 5'-CTGGAGACGCAGCACAAG-3' } \\
\text { 5'-GACAGTTGCTCCACCTTCTTC-3' }\end{array}$ & 74 \\
\hline SREBF1 & AB355703.1 & $\begin{array}{l}\text { 5'-CAATGTGTGAGAAGGCCAGT-3' } \\
\text { 5'-ACAAGGAGCAGGTCACACAG-3' }\end{array}$ & 109 \\
\hline ADIPOQ & NM_174742.2 & $\begin{array}{l}\text { 5'-CACTGTTCCCAATGTACCCA-3' } \\
\text { 5'-TCATGTACACCGTGATGTGG-3' }\end{array}$ & 137 \\
\hline LEP & NM_173928.2 & $\begin{array}{l}\text { 5'-TGACATCTCACACACGCAGT-3' } \\
\text { 5'-AGGGATGAAGTCCAAACCAG-3' }\end{array}$ & 64 \\
\hline LEPR & NM_001012285.2 & $\begin{array}{l}\text { 5'-TCAATTGGTGCTTCTTCTGC-3' } \\
\text { 5'-ATTGTAATCGCTGGGTGACA-3' }\end{array}$ & 144 \\
\hline GAPDH & NM_001034034.1 & $\begin{array}{l}\text { 5'-CCAACGTGTCTGTTGTGGAT-3' } \\
\text { 5'-CTGCTTCACCACCTTCTTGA-3' }\end{array}$ & 80 \\
\hline ACTB & NM_173979.3 & $\begin{array}{l}\text { 5'-CTCTCTTCCAGCCTTCCTTC-3' } \\
\text { 5'-GTAGAGGTCCTTGCGGATGT-3' }\end{array}$ & 104 \\
\hline
\end{tabular}

\section{Statistical analysis}

Statistical analysis was performed using SPSS 13.0. All results are reported as means \pm standard deviation (SD). Statistical differences between the AD-FABP4 treatment groups and $\mathrm{AD}-\mathrm{NC}$ control groups were compared by one-way analysis of variance (ANOVA) followed by the post hoc Duncan test. P less than 0.05 and P less than 0.01 were considered to be statistically significant or very significant, respectively. 


\section{RESULTS}

\section{Initial selection of effective shRNA and adenovirus preparation}

Construction of pENTR/CMV-GFP/U6-shRNA and pDsRed1-C1-FABP4 was confirmed by $S c a$ I and BamHI plus $X$ hoI enzyme digestion, respectively (Figure 1), followed by sequencing. FABP4 and pDsRed1-C1 vector-derived RFP were co-expressed as a fusion protein (FABP4-RFP) in HEK 293A cells by pDsRed1-C1-FABP4. In co-transfected pENTR/CMV-GFP/U6-shRNA and pDsRed1-C1-FABP4 cell plates, effective shRNA (targeted FABP4) reduced the red fluorescence by partially silencing the FABP4-RFP mRNA. According to the diminished degree of red fluorescence, the most effective shRNA 261 was observed (Figure 2). Moreover, green fluorescence expressed by the single pENTR/ $\mathrm{CMV}-\mathrm{GFP} / \mathrm{U} 6-$ transfected group was similar between groups, indicating that there was no difference in transfection efficiency. pENTR/CMV-GFP/U6-shRNA 261 and pENTR/CMVGFP/U6-shRNA-NC were then recombined with pAD/BLOCK-IT ${ }^{\mathrm{TM}}$-DEST, respectively. After the confirmation of $P a c \mathrm{I}$ enzyme digestion (Figure 3) and sequencing, adenovirus AD-FABP4 (shRNA adenovirus against FABP4 and derived from shRNA 261) and AD-NC (control shRNA adenovirus and derived from shRNA-NC) were produced by the positive plasmids. Infectious adenovirus was then used to infect the bovine-derived preadipocytes. GFP expressions after $72 \mathrm{~h}$ infection of AD-FABP4 to preadipocytes are shown in Figure 4.

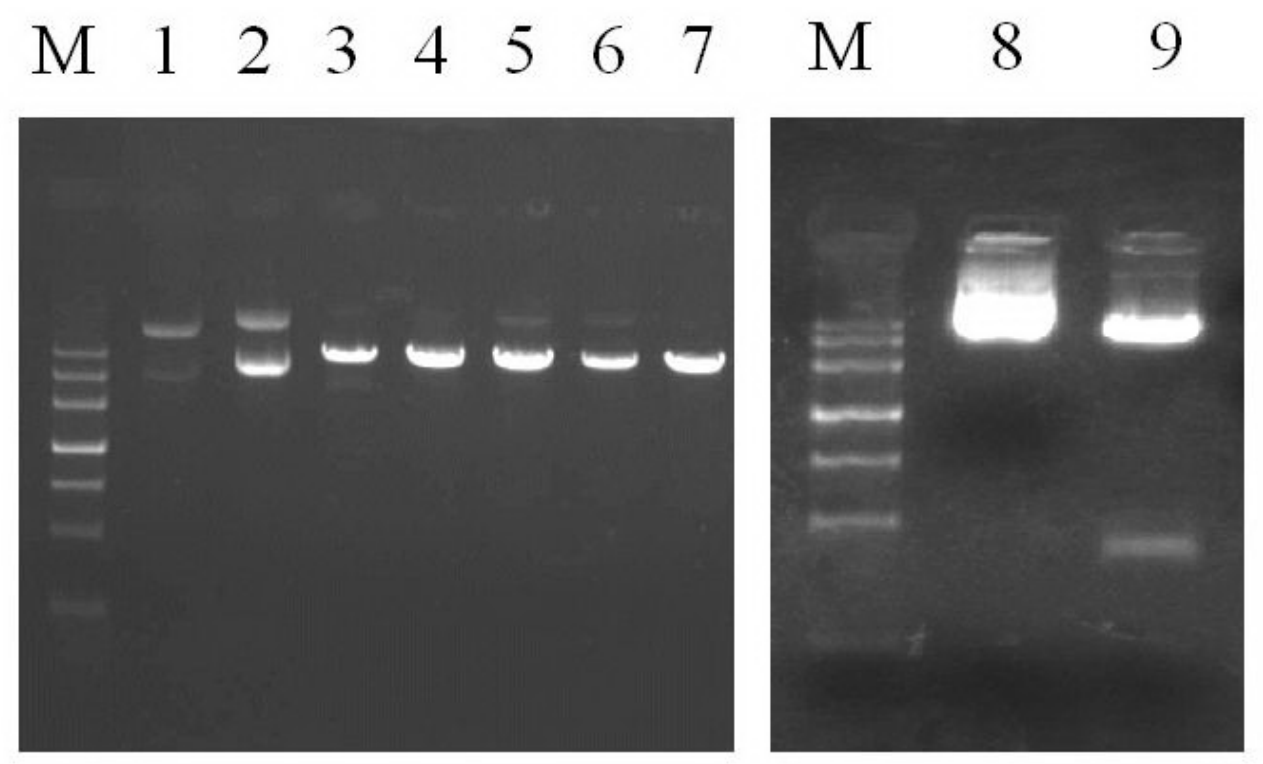

Figure 1. Indentification of enzyme digestion for pENTR/CMV-GFP/U6-shRNA and pDsRed1-C1-FABP4 plasmids. Lane $M=$ Marker III (Tiangen) containing 4500, 3000, 2000, 1200, 800, 500, and 200 ladders. Lanes 1 and $2=\mathrm{pENTR} / \mathrm{CMV}-\mathrm{GFP} / \mathrm{U} 6$-shRNA. Lanes 3 to $7=\mathrm{ScaI}$ digestion of pENTR/CMV-GFP/U6-shRNA. Lane $8=$ pDsRed1-C1-FABP4. Lane 9 = Dual-enzyme digestion of XhoI plus BamHI for pDsRed1-C1-FABP4; the fractions were about 4700 and $414 \mathrm{bp}$, respectively. 


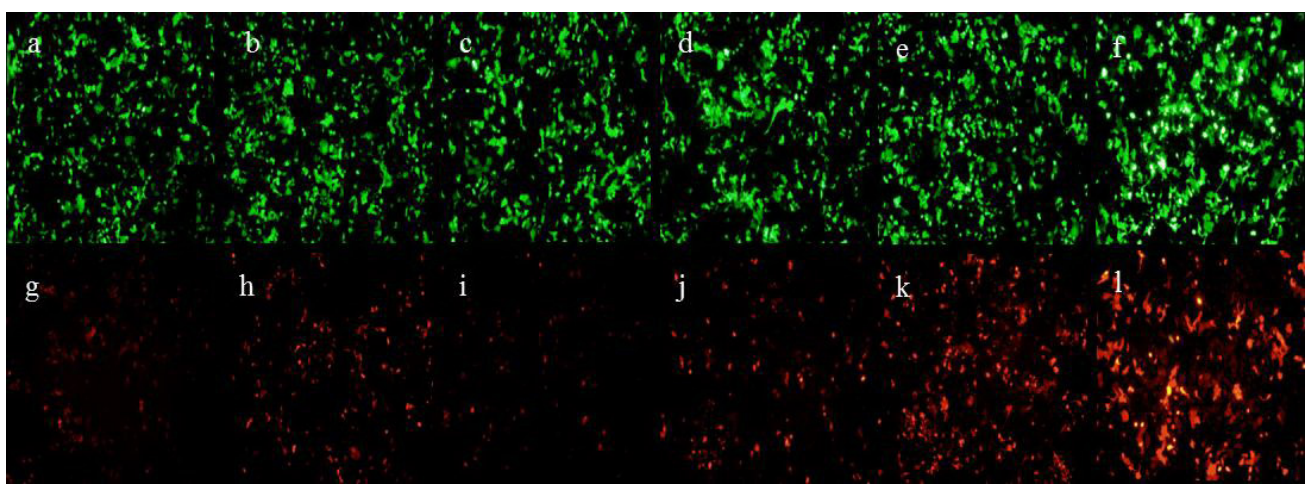

Figure 2. Initial selection of effective shRNA. Co-transfection of pDsRed1-C1-FABP4 with pENTR/CMV-GFP/ U6/shRNA 202-220 (a, g), pENTR/CMV-GFP/U6/shRNA 207-225 (b, h), pENTR/CMV-GFP/U6/shRNA 261279 (c, i), pENTR/CMV-GFP/U6/shRNA 304-322 (d, j), pENTR/CMV-GFP/U6/shRNA-NC (e, k). The green fluorescence of upper panels (a to e) shows similar transfection efficiencies among groups; the lower panels ( $\mathbf{g}$ to k) shows the different shRNA efficiencies by diverse red fluorescence degree. Single transfection effect of pENTR/ CMV-GFP/U6/shRNA-NC (f), pDsRed1-C1-FABP4 (l) is shown. From (g to k), pENTR/CMV-GFP/U6/shRNA 261-279. (i) had the lowest red fluorescence comparing with other groups. All photomicrographs were taken by an Olympus inverted research microscope (100X magnification).

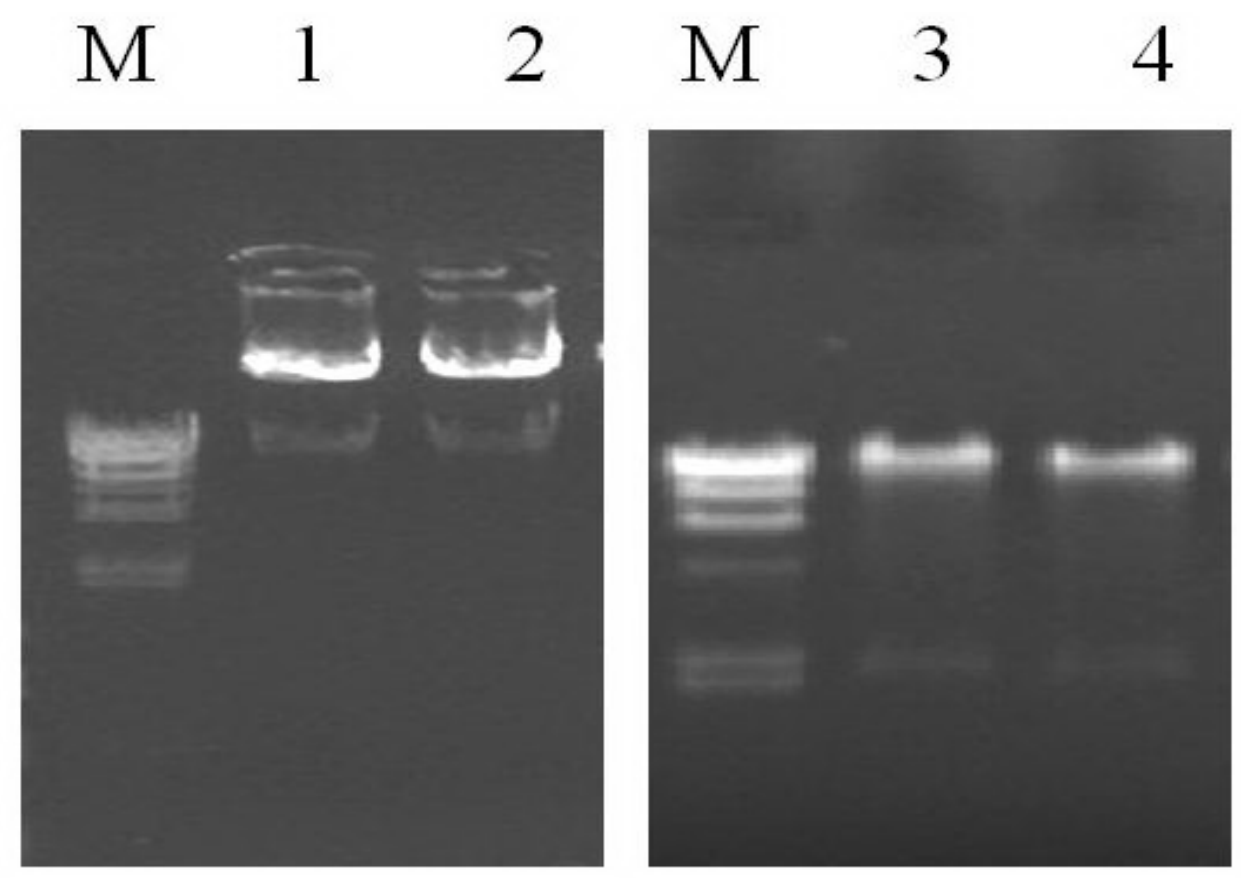

Figure 3. Identification of $\mathrm{PacI}$ digestion for pAD/PL-DEST/CMV-GFP/U6-shRNA. Lane $M=\lambda$-HindIII digest marker (Takara) containing 23130, 9416, 6557, 4361, 2322, 564, and 125 ladders. Lanes 1 and 2 = pAD/PL-DEST/ CMV-GFP/U6-shRNA 261 and pAD/PL-DEST/CMV-GFP/U6-shRNA-NC. Lanes 3 and $4=$ PacI digestion of pAD/PL-DEST/CMV-GFP/U6-shRNA 261 and pAD/PL-DEST/CMV-GFP/U6-shRNA-NC; the fractions were about 30 and $2 \mathrm{~kb}$, respectively. 

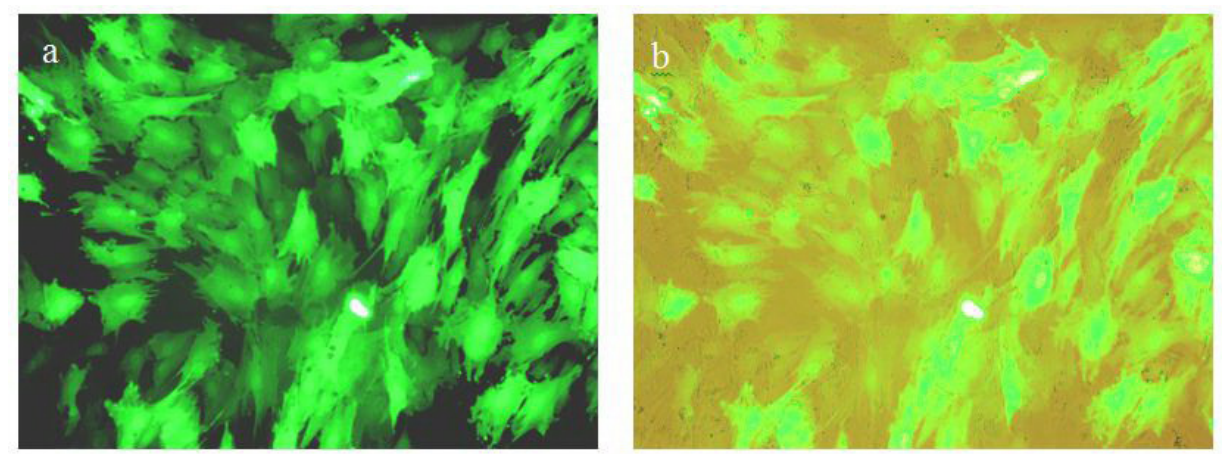

Figure 4. Seventy-two hours after AD-FABP4 infection to bovine preadipocytes. (a) Fluorescent photograph in dark field; (b) fluorescent photograph in light field. All photomicrographs were taken by an Olympus inverted fluorescent microscope (200X magnification).

\section{Interferential efficiency of AD-FABP4 and influence on mRNA expression of other related genes}

In this experiment, effective AD-FABP4 was designed and constructed successfully; it decreased FABP4 mRNA by $41(\mathrm{P}<0.01)$ and $66 \%(\mathrm{P}<0.01)$ at 24 and $72 \mathrm{~h}$, respectively. After $24 \mathrm{~h}$ of AD-FABP4 infection, with $41 \%$ interference efficiency of FABP4, ADIPOQ and LEP resulted in a $41(\mathrm{P}<0.05)$ and $73 \%(\mathrm{P}<0.01)$ decrease, respectively, compared with the AD-NC treatment groups. However, the expression of differentiation-related genes (PPAR, CEBPA, CEBPB, and SREBF1) was not influenced significantly by down-regulation of the FABP4 gene at this time $(\mathrm{P}=0.54,0.78,0.89$, and 0.94 , respectively) (Figure 5$)$. At $72 \mathrm{~h}$ after AD-FABP4 infection, when FABP4 decreased 66\%, the expression of ADIPOQ and LEP genes decreased by $57 \%(\mathrm{P}<0.01)$ and $80 \%(\mathrm{P}<0.01)$, respectively. Meanwhile, LEPR gene expression increased 6.75-fold $(\mathrm{P}<0.01)$ (Figure 6). The results suggest that FABP4 may play a role in regulating lipid metabolism-related genes (such as ADIPOQ, LEP and LEPR), without affecting the ability of preadipocytes to differentiate to adipocytes.

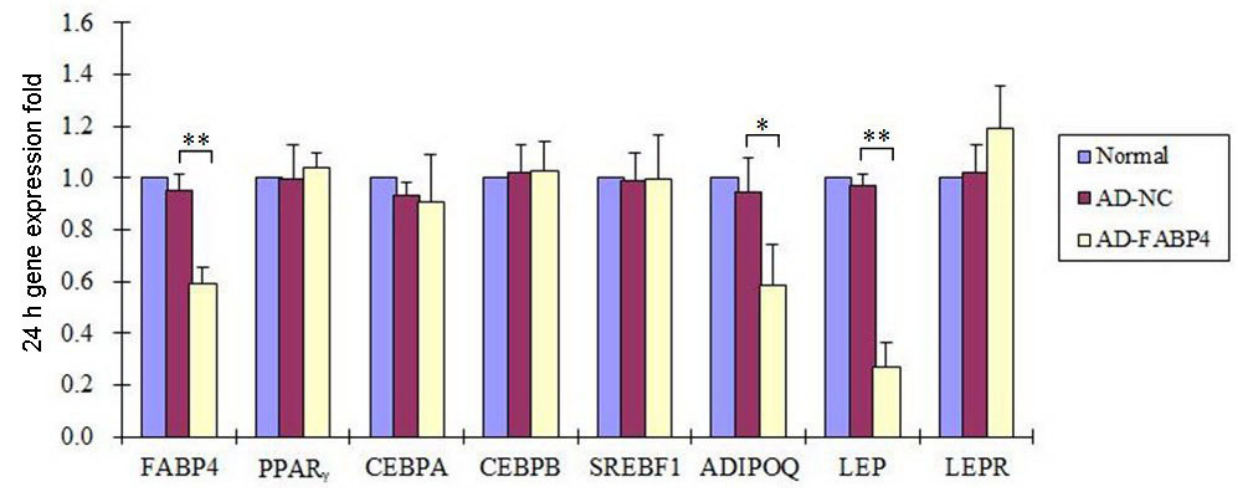

Figure 5. Real-time PCR results of FABP4 and other related genes at $24 \mathrm{~h}$ after adenovirus treatment. AD-FABP4 columns with 1 asterisk are significantly different $(\mathrm{P}<0.05)$ comparing with AD-NC groups while columns with 2 asterisks are significantly different $(\mathrm{P}<0.01)$. 


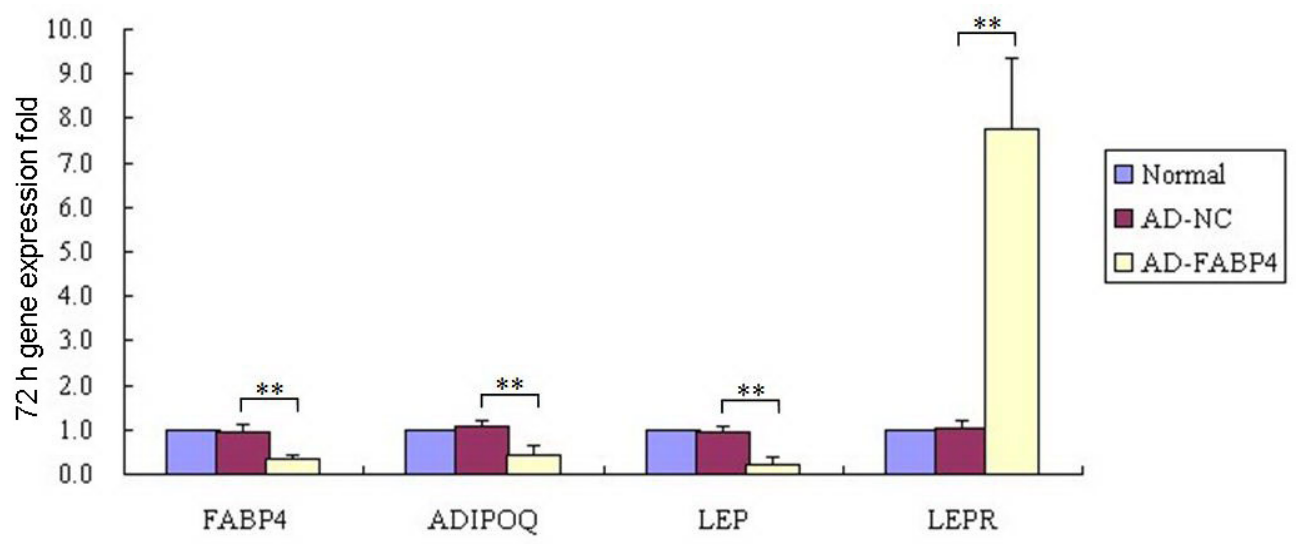

Figure 6. Real-time PCR results of FABP4 and other related genes at $72 \mathrm{~h}$ after adenovirus treatment. AD-FABP4 columns with asterisks are significantly different $(\mathrm{P}<0.01)$ comparing with $\mathrm{AD}-\mathrm{NC}$ groups.

\section{DISCUSSION}

Studies have focused on the relationship between FABP4 and economic traits in cattle. Jurie et al. (2007) showed that FABP4 protein content in muscle was correlated with triacylglycerol content. Hoashi et al. (2008) identified that FABP4 was associated with palmitoleic acid composition in intramuscular fat of Japanese Black cattle. Similar findings were published by Mannen (2011) and Narukami et al. (2011) in Holstein steers. Moreover, other research also suggested that bovine FABP4 was associated with beef tenderness (Zhao et al., 2012), marbling (Michal et al., 2006; Barendse et al., 2009; Lee et al., 2010), subcutaneous fat depth (Michal et al., 2006), and carcass weight (Lee et al., 2010), indicating the importance of FABP4 on animal carcass composition. Thus, the function of bovine FABP4 at the cellular level needs to be determined.

shRNA interference was used in this study to detect the gene function of bovine FABP4. DNA plasmid and virus vectors are the main shRNA carriers, showing priority to unstable non-vector system. However, usage of DNA plasmid vectors results in low transfection efficiency in primary cultured cells. Owing to high efficiency and safety of manipulating the adenovirus system, in this experiment, adenovirus-mediated shRNA was selected to decrease FABP4 gene expression of bovine preadipocytes. To get effective shRNA, four pairs of shRNA were designed and compared by first co-transfecting pENTR/CMV-GFP/U6-shRNA and pDsRed1-C1-FABP4 239A cells. Through this system, the best shRNA could be picked by the fluorescence efficiently without extensive time and/or materials. Here, we showed that shRNA 261, with the lowest red fluorescence after co-transfection, had the highest interferential efficiency and could be used for subsequent adenovirus recombination and packaging. In HEK 293A cells, red fluorescent diminish degree of the shRNA 261 group by more than $80 \%$ compared with the shNC group after 3 days of transfection. However, real-time PCR showed that final adenovirus AD-FABP4 had $66 \%$ interferential efficiency with primary bovine preadipocytes. The reason may be associated with the specific differences, different cell types and the different contents of FABP4 in adipocytes.

In addition to the gene coding region, siRNA could target UTR as well, especially the 
3'-UTR in animals. However, these regions usually contain binding sequences for regulatory proteins, which may affect siRNA interference. Therefore, in this experiment, just the coding region was selected to test shRNA, although there are some reports of silencing the expression of several genes by targeting the UTR (Yu et al., 2002). Recently, Bork et al. (2011) suggested that 3'-UTR of FABP4 may be a direct target of human miR-369-5p. Considering that the FABP4 3'-UTR of human and bovine has $78 \%$ identity, it will be interesting to detect the bovine miR-369-5p functions and further compare the interferential efficiency of the miR369-5p and shRNA 261 detected in this experiment.

Peroxisome proliferator-activated receptor gamma $\left(\mathrm{PPAR}_{\gamma}\right)$ was expressed in the early phase of bovine preadipocyte differentiation and is considered a critical transcription factor (Hirai et al., 2007a,b). We hypothesized that FABP4, as a downstream gene of the PPAR signaling pathway, could influence adipocyte differentiation and conformation via changing the fatty acids and acting through feedback regulation. Moreover, as adipogenesis is closely related to meat quality and fat deposition (Hausman et al., 2009; Dodson et al., 2010a, c), studies in this area are important for animal production. Therefore, several differentiationrelated genes $\left(\mathrm{PPAR}_{\gamma}, \mathrm{CEBPA}, \mathrm{CEBPB}\right.$, and SREBF1) were detected after $24 \mathrm{~h}$ of AD-FABP interference, when these genes play key roles in regulating adipocyte differentiation. However, our study showed that, with a $41 \%$ decrease in FABP 4 mRNA expression after $24 \mathrm{~h}$ of ADFABP4 treatment, the expression of these genes was not affected, indicating that FABP4 may not influence the differentiation of preadipocytes to fat cells. This result is consistent with FABP4 knockout mice reported by Hotamisligi et al. (1996), who first showed that mice with decreased FABP4 level seemed to develop adipocytes normally.

Adipose tissue is not only an energy depot but also an endocrine organ, secreting a variety of bioactive substances (called adipokines), which are actively involved in insulin sensitivity, and glucose and lipid metabolism. ADIPOQ (adiponectin) has been identified as a susceptibility locus for the metabolic syndrome, type 2 diabetes mellitus and cardiovascular disease (Vionnet et al., 2000; Francke et al., 2001). LEP (leptin) and LEPR (leptin receptor) can have a profound impact on body weight, insulin resistance and other metabolic disease parameters (Enns et al., 2011). An additional study showed that variations in ADIPOQ, LEP and LEPR (adipokines) are associated with risk for obesity-related metabolic disease (Francke et al., 2001), which have a similar function as FABP4. Thus, in this study, ADIPOQ, LEP and LEPR, which are associated with lipid metabolism (Vionnet et al., 2000; Witthuhn and Bernlohr, 2001; Francke et al., 2001; Enns et al., 2011), were selected to determine the relationship with FABP4. In our study, by partially silencing bovine FABP4, ADIPOQ and LEP were found to decrease by $41(\mathrm{P}<0.05)$ and $73 \%(\mathrm{P}<0.01)$ following a $24-\mathrm{h}$ interference period. A 72-h treatment was then performed to detect their relationship. The results showed that with a $66 \%$ decrease in FABP4 mRNA content, all three of these lipid metabolism-related genes were extensively affected $(\mathrm{P}<0.01)$, with a 57 and $80 \%$ decrease in ADIPOQ and LEP gene expression, respectively, and a 6.75-fold increase in LEPR mRNA expression. These results suggest that FABP4 may play a vital role in regulating lipid metabolism-related genes in the complicated gene network of adipocytes.

In conclusion, we first designed and selected effective shRNA targeting bovine FABP4, which decreased FABP4 mRNA expression by $66 \%$, providing a guide for others to directly assess bovine FABP4 gene function studies. Furthermore, a preliminary test of FABP4 function was performed by detecting the relationship with differentiation-related genes and 
lipid metabolism-related genes. The results showed that lower FABP4 levels did not affect the differentiation-related genes $\left(\mathrm{PPAR}_{\gamma}, \mathrm{CEBPA}, \mathrm{CEBPB}\right.$, and SREBF1). Yet, we first discovered that ADIPOQ, LEP and LEPR genes were associated with FABP4 directly, and that lower FABP4 levels decreased ADIPOQ and LEP mRNA expression, while increasing LEPR gene expression, in bovine adipocytes. Collectively, FABP4 may play a role in regulating lipid metabolism-related genes (such as ADIPOQ, LEP and LEPR), without affecting the differentiation ability of preadipocytes. As FABP4 has been indicated as a biomarker for high quality of beef (Michal et al., 2006; Jurie et al., 2007; Hoashi et al., 2008; Barendse et al., 2009; Lee et al., 2010; Mannen, 2011; Narukami et al., 2011; Zhao et al., 2012) or human disease (Hotamisligil et al., 1996; Tuncman et al., 2006; Xu et al., 2006; Furuhashi et al., 2007) in previous studies, our research will provide a basis for further studies of bovine FABP4 functions and the involvement of FABP4 in gene signaling pathways.

\section{ACKNOWLEDGMENTS}

Research supported by the China National Twelfth “Five Year"Science and Technology Support Project (\#2011BAD28B04-03), the China National 863 Program (\#2011AA100307), the China GMO New Varieties Major Project (\#2011ZX08007-002), the China National Beef and Yak Industrial Technology System (CARS-38), the Program for Changjiang Scholars and Innovative Research Team of China (IRT0940), and the National Natural Science Foundation of China (\#31272411, \#31000998).

\section{REFERENCES}

Barendse W, Bunch RJ, Thomas MB and Harrison BE (2009). A splice site single nucleotide polymorphism of the fatty acid binding protein 4 gene appears to be associated with intramuscular fat deposition in longissimus muscle in Australian cattle. Anim. Genet. 40: 770-773.

Bork S, Horn P, Castoldi M, Hellwig I, et al. (2011). Adipogenic differentiation of human mesenchymal stromal cells is down-regulated by microRNA-369-5p and up-regulated by microRNA-371. J. Cell Physiol. 226: 2226-2234.

Dodson MV, Jiang Z, Chen J, Hausman GJ, et al. (2010a). Allied industry approaches to alter intramuscular fat content and composition in beef animals. J. Food Sci. 75: R1-R8.

Dodson MV, Hausman GJ, Guan L, Du M, et al. (2010b). Skeletal muscle stem cells from animals I. Basic cell biology. Int. J. Biol. Sci. 6: 465-474.

Dodson MV, Hausman GJ, Guan L, Du M, et al. (2010c). Lipid metabolism, adipocyte depot physiology and utilization of meat animals as experimental models for metabolic research. Int. J. Biol. Sci. 6: 691-699.

Enns JE, Taylor CG and Zahradka P (2011). Variations in Adipokine Genes AdipoQ, Lep, and LepR are Associated with Risk for Obesity-Related Metabolic Disease: The Modulatory Role of Gene-Nutrient Interactions. J. Obes. 2011: 168659.

Fernyhough ME, Okine E, Hausman G, Vierck JL, et al. (2007). PPARgamma and GLUT-4 expression as developmental regulators/markers for preadipocyte differentiation into an adipocyte. Domest. Anim. Endocrinol. 33: 367-378.

Fire A, Xu S, Montgomery MK, Kostas SA, et al. (1998). Potent and specific genetic interference by double-stranded RNA in Caenorhabditis elegans. Nature 391: 806-811.

Francke S, Manraj M, Lacquemant C, Lecoeur C, et al. (2001). A genome-wide scan for coronary heart disease suggests in Indo-Mauritians a susceptibility locus on chromosome 16p13 and replicates linkage with the metabolic syndrome on 3q27. Hum. Mol. Genet. 10: 2751-2765.

Furuhashi M, Tuncman G, Görgün CZ, Makowski L, et al. (2007). Treatment of diabetes and atherosclerosis by inhibiting fatty-acid-binding protein aP2. Nature 447: 959-965.

Hausman GJ, Dodson MV, Ajuwon K, Azain M, et al. (2009). Board-invited review: the biology and regulation of preadipocytes and adipocytes in meat animals. J. Anim. Sci. 87: 1218-1246.

Hirai S, Matsumoto H, Moriya NH, Kawachi H, et al. (2007a). Follistatin rescues the inhibitory effect of activin A on the 
differentiation of bovine preadipocyte. Domest. Anim. Endocrinol. 33: 269-280.

Hirai S, Matsumoto H, Hino N, Kawachi H, et al. (2007b). Myostatin inhibits differentiation of bovine preadipocyte. Domest. Anim. Endocrinol. 32: 1-14.

Hoashi S, Hinenoya T, Tanaka A, Ohsaki H, et al. (2008). Association between fatty acid compositions and genotypes of FABP4 and LXR-alpha in Japanese black cattle. BMC Genet. 9: 84.

Hotamisligil GS, Johnson RS, Distel RJ, Ellis R, et al. (1996). Uncoupling of obesity from insulin resistance through a targeted mutation in aP2, the adipocyte fatty acid binding protein. Science 274: 1377-1379.

Jurie C, Cassar-Malek I, Bonnet M, Leroux C, et al. (2007). Adipocyte fatty acid-binding protein and mitochondrial enzyme activities in muscles as relevant indicators of marbling in cattle. J. Anim. Sci. 85: 2660-2669.

Lee SH, van der Werf JH, Lee SH, Park EW, et al. (2010). Genetic polymorphisms of the bovine fatty acid binding protein 4 gene are significantly associated with marbling and carcass weight in Hanwoo (Korean Cattle). Anim. Genet. 41: $442-444$.

Mannen H (2011). Identification and utilization of genes associated with beef qualities. Anim. Sci. J. 82: 1-7.

Michal JJ, Zhang ZW, Gaskins CT and Jiang Z (2006). The bovine fatty acid binding protein 4 gene is significantly associated with marbling and subcutaneous fat depth in Wagyu x Limousin F2 crosses. Anim. Genet. 37: 400-402.

Narukami T, Sasazaki S, Oyama K, Nogi T, et al. (2011). Effect of DNA polymorphisms related to fatty acid composition in adipose tissue of Holstein cattle. Anim. Sci. J. 82: 406-411.

Ockner RK, Manning JA, Poppenhausen RB and Ho WK (1972). A binding protein for fatty acids in cytosol of intestinal mucosa, liver, myocardium, and other tissues. Science 177: 56-58.

Poulos SP, Dodson MV and Hausman GJ (2010). Cell line models for differentiation: preadipocytes and adipocytes. Exp. Biol. Med. 235: 1185-1193.

Sun YG, Zan LS, Wang HB, Guo HF, et al. (2009). Insulin inhibits the expression of adiponectin and adipoR2 mRNA in cultured bovine adipocytes. Asian-Aust. J. Anim. Sci. 22: 1429-1436.

Taniguchi M, Guan LL, Basarab JA, Dodson MV, et al. (2008a). Comparative analysis on gene expression profiles in cattle subcutaneous fat tissues. Comp. Biochem. Physiol. Part D Genomics Proteomics 3: 251-256.

Taniguchi M, Guan LL, Zhang B, Dodson MV, et al. (2008b). Gene expression patterns of bovine perimuscular preadipocytes during adipogenesis. Biochem. Biophys. Res. Commun. 366: 346-351.

Tuncman G, Erbay E, Hom X, De Vivo, I, et al. (2006). A genetic variant at the fatty acid-binding protein aP2 locus reduces the risk for hypertriglyceridemia, type 2 diabetes, and cardiovascular disease. Proc. Natl. Acad. Sci. U. S. A. 103: 6970-6975.

Tuschl T (2001). RNA interference and small interfering RNAs. Chembiochem 2: 239-245.

Vionnet N, Hani EH, Dupont S, Gallina S, et al. (2000). Genomewide search for type 2 diabetes-susceptibility genes in French whites: evidence for a novel susceptibility locus for early-onset diabetes on chromosome 3q27-qter and independent replication of a type 2-diabetes locus on chromosome 1q21-q24. Am. J. Hum. Genet. 67: 1470-1480.

Witthuhn BA and Bernlohr DA (2001). Upregulation of bone morphogenetic protein GDF-3/Vgr-2 expression in adipose tissue of FABP4/aP2 null mice. Cytokine 14: 129-135.

Xu A, Wang Y, Xu JY, Stejskal D, et al. (2006). Adipocyte fatty acid-binding protein is a plasma biomarker closely associated with obesity and metabolic syndrome. Clin. Chem. 52: 405-413.

Yu JY, DeRuiter SL and Turner DL (2002). RNA interference by expression of short-interfering RNAs and hairpin RNAs in mammalian cells. Proc. Natl. Acad. Sci. U. S. A. 99: 6047-6052.

Zhao C, Tian F, Yu Y, Luo J, et al. (2012). Muscle transcriptomic analyses in Angus cattle with divergent tenderness. Mol. Biol. Rep. 39: 4185-4193. 